\title{
Research-based College English Blended Teaching of Fashion Major: A Case Study of Beijing Institute of Fashion Technology
}

\author{
Weili Zi ${ }^{1}$, Yiling Zhou ${ }^{2}$ \\ ${ }^{1}$ School of Language and Culture, Beijing Institute of Fashion Technology, Beijing, China \\ ${ }^{2}$ Basic Teaching Department, Beijing Institute of Fashion Technology, Beijing, China. \\ Correspondence: Weili Zi, School of Language and Culture, Beijing Institute of Fashion Technology, Beijing, China.
}

Received: June 19, 2020

doi:10.11114/ijce.v3i2.4935

Accepted: July 19, 2020

Online Published: July 20, 2020

URL: https://doi.org/10.11114/ijce.v3i2.4935

\begin{abstract}
With the further development of "the reform and open", and the strategically stable advancement of "going out", there is increasingly demand for foreign language talents and foreign language education. Research-based College English Blended Teaching just adapts to the national demand for international fashion talents with the international vision and the ability to participate in the international competition, which also provides us with opportunity to integrate the information technology with subject teaching. With the A-level class of grade 2018 from Beijing Institute of Fashion Technology (BIFT) as the case, the blended teaching theory as the guidance, this research presents the way of practice in research-based college English blended teaching by making use of the instrumental features of college English with the aim of cultivating students' professional research ability and academic communication ability. The study shows that remarkable results have been achieved in research-based blended teaching after three-semester practice-students could independently deliver academic presentation and conduct research in English individually or collaboratively in the professional field. The practice and exploration of the efficiency in research-based College English blended teaching could enhance the ability of academic presentation and academic writing of fashion majors, and promote their academic achievements for high-quality international fashion talents. Therefore, research-based College English blended teaching, integrating English skills with professional knowledge, is proved to be definitely instructive, implicational and exemplary to reform college English teaching in fashion field.
\end{abstract}

Keywords: blended teaching, students of fashion major, research-based College English teaching, practice

\section{Introduction}

Wu Yan (2019), Director of higher education department in the ministry of education, ever stressed in the report of the fourth high-level forum on the reform and development of foreign language education in national institutions of higher learning, that higher foreign language education is an important part of higher education, with its wide coverage, large size and great responsibility, especially its irreplaceable role in teaching of higher education. Therefore, facing the current reform and development trend of higher foreign language education, participation in reform and change in college English teaching is pressing in cultivating the fashion talents to adapt to the global educational development.

If innovation is regarded as the lifeblood to higher education, reform and innovation of college English teaching is the key to cultivation of fashion talents, which refers to those interdisciplinary talents with one or more professions and multi-foreign languages, that is, to cultivate first-class fashion talents who are competent in professional ability and know foreign languages at the same time. Beijing Institute of Fashion Technology (BIFT) is an art-engineering oriented full-time arts college named after clothes, with the multi-disciplinary coordinated development, including arts, engineering, finance and management. BIFT established the cooperation and the exchange relations with many foreign famous schools of fashion design, such as University of the Arts London, New York Fashion College, Parsons School of Design, New York, Polytechnic University of Milan, etc., and other more than 40 foreign universities, which requires students of strong professional competence and higher international communication skills .

This paper intends to present research-based college English teaching practice of fashion major in a blended teaching environment, based on the combination of enforcement of proficiency in using English and enhancement of academic ability with BIFT as the case. The practice aims at laying a solid foundation for cultivation of first-class fashion talents with a good command of English, strong academic ability and professional communication skills. 


\section{Literature Review}

\subsection{Blended Teaching}

The network teaching platform is the premise of carrying out blended teaching, for blended teaching could provide students with enough learning hours, ensuring the in-class teaching and learning efficiency. Generally, the difficulties and the key parts are dealt with in class, including common problems as the feedback from students while autonomously learning online. Blended teaching is usually conducted through the online education integrated platform in BIFT. For students participating in this learning, three stages are required for each class, including before-class (online study), in-class (offline class or online class) and after-class (online study) with the aim of making classroom teaching more targeted.

He Kekang (2004), the famous professor in blending teaching field, maintains that blended learning is a method of combination of the traditional learning with its unique advantage and E-learning (i.e. digital or networked learning), the purpose of which is not only to ensure the leading role of teachers' guidance and inspiration in monitoring the teaching process, but also to present initiative, enthusiasm and creativity of students as the subject of the learning process.

Blended teaching is the reconstruction of traditional class, and effective extension of traditional teaching both in time and space. It renders important and difficult teaching points clearer, and enables students' autonomous learning ability to be further enhanced, which would be more conducive to the expansion and extension of what have been learnt. Of course, research-based teaching in blended environment is also the expansion and extension of what have been taught. The research-based teaching practice is conducted to enhance students' professional and academic communication skills while improving students' comprehensive cultural quality, Language proficiency, and finally to achieve the goal of increased international competitiveness of fashion majors.

\subsection{Domestic Related Research Status}

\subsubsection{Focus and Trends of Domestic Related Research}

The earlier academic research related to blended teaching mode is from the article Mixed Teaching in Network Environment --- a new teaching mode written by Yu, Liu, and Chen (2005), which was published in Chinese Journal of University Education in October, 2005. The author in this article introduced the specific content and evolution procedure of blended teaching method in detail, and especially the idea of "It is a completely new teaching method" is emphasized in the conclusion part, advocating the combination of traditional teaching and digitalized teaching with their unique advantages for achieving better teaching results. This article was cited 6154 times so far. In November, 2005, doctor LiuHuang, Huang, Zhu, and Zheng (2005) published an article An Action Study of Blended Teaching in journal Academic Degrees \& Graduate Education, giving a detailed account of the process of 4-year blended teaching with the summary of five problems to pay attention to in conclusion part, which indeed provides the latest related research with enlightenment and inspiration. This article was so far cited 1144 times.

For further knowledge of the trends over blended teaching researches in higher education, "College English blended teaching (learning)" as search terms was input on China National Knowledge Infrastructure (CNKI), and 548 related articles during 2005-2019 were retrieved. As is shown in Figure 1, the research over college English blended teaching shows a steady trend during 2005 and 2014. Since 2015, more researchers participated in exploring the effect of blended teaching mode along with the growing social demand for teaching reform.

According to the analysis, time between 2005 and 2009 belonged to the early stage of the study, during which researches mainly focused on the recognition and knowledge of blended teaching concept, mode and methods. The researches over blended teaching seemed to hit a plateau from 2009 to 2014; during this period, theoretical researchers were more influential while mostly exploring the concept and the mode of blended teaching with quite more disputes in this research field. With more in-depth researches, researchers are mostly reaching unanimity over the characteristics and the mode of blended teaching and learning and attract many more researchers to involve themselves into examining the role the blended teaching mode plays in teaching field. Then, researches were increasing progressively since 2015, and peaked in 2019, which indicates the maturity and extensive application of researches on blended teaching mode in higher education, and which also shows its popularity in teaching while emphasizing the idea that it is one of key teaching means in college English teaching field. 
Note: Article Counts: 548; Search Condition :( subject=College English blended teaching/learning or title=College English blended teaching/learning) (fuzzy matching)

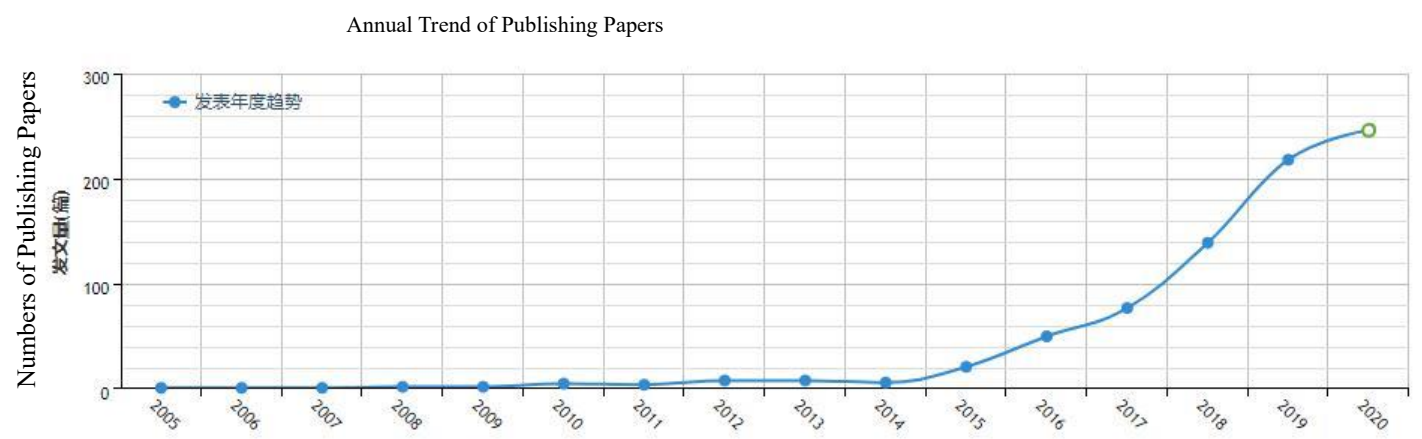

Figure 1. Research Trend of College English Teaching under B-learning during 2005-2019

Since 2014, further researches on College English blended teaching are conducted depending on different platforms, mainly targeting blended teaching mode, the intercultural teaching under the mixed mode, blended teaching design, relationship between autonomous study and blended study, etc.. (Huang et al.,2014; Yang et al., 2017; Wang, 2017; Suo, 2018; Zhang et al., 2019; Liao et al., 2019) As it is shown in Figure 2, during 2005-2019, most related researches primarily focus on college English teaching, college learning mode, and blended teaching model; of course some of them also involve the teaching mode of flipped classroom. However, the diachronic analysis of the literature shows fewer researchers incorporate research-based teaching into College English class under blended environment, namely, the interdisciplinary blended teaching is conducted by combining language skills with professional knowledge. It is the truth that English teaching serves for professional learning. In other words, instrument (such as English) serves for content (such as professional knowledge), English skill indeed promotes professional improvement, for those with a good command of English could be good at reading foreign professional materials and skillful for academic communication. So, to cultivate students' academic communication ability while motivating their study interest needs more effective teaching mode to improve its international competitiveness in the field of fashion.

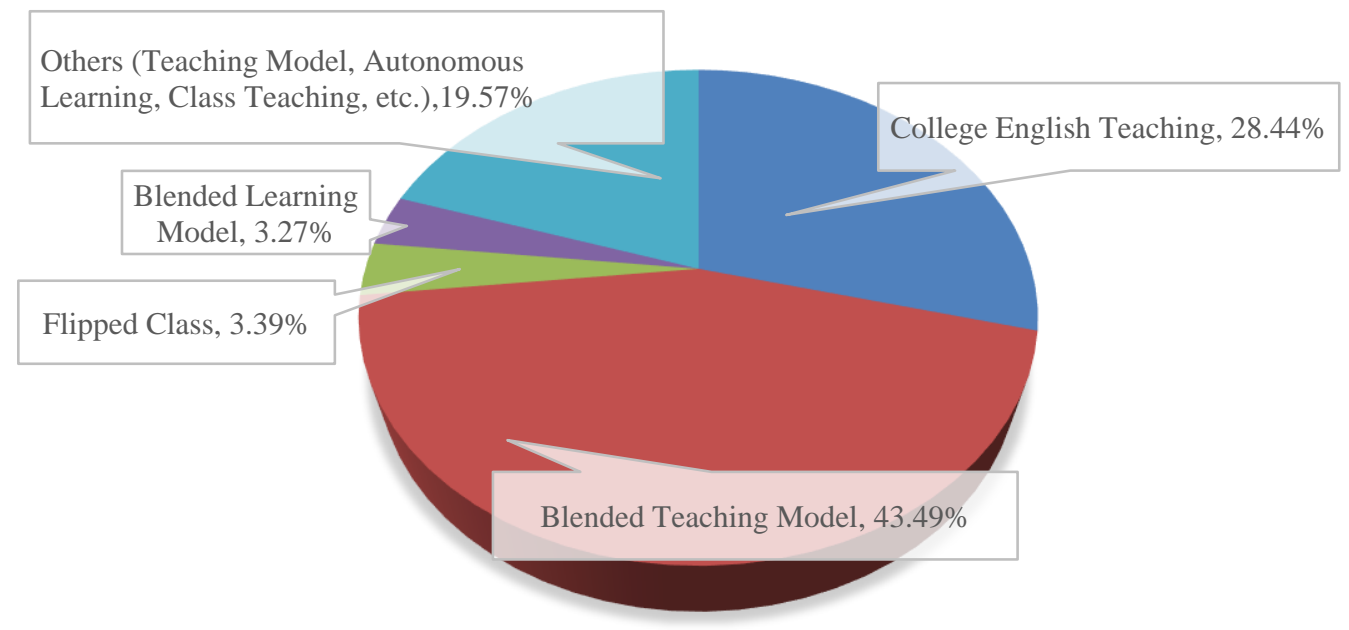

Figure 2. Research Topics over College English Teaching under Blended Environment during 2005-2019

Besides, there is a certain difference in topics, methods and the like for the related researches both home and abroad. Ma Zhiqiang, Kong Lili, and Zeng Ning (2015), who are from Jiangnan University, have made an analysis of trends over blended teaching researches within recent ten years (2005-2015). The findings show that domestic academic dissertations over blended learning mainly focus on curriculum level in higher education. And as to methods of blended teaching, such topics are mainly concerned, including teaching design, learning effect analysis, comparison between blended learning and face-to-face teaching and learning, technology application related to blended teaching (Ma et al., 2015; 2016). Following that, multidimensional analysis of the articles over blended learning in SSCI and CSSCI 
journals during 2005-2015 shows that blended learning researches both home and abroad are closely related to online study, distance study and higher education, but the starting-points of the research over blended teaching design differ in research topics - domestic research tends to conduct the empirical study after constructing blended learning mode theoretically, while the research abroad is more inclined to propose and verify the blended teaching strategy and method over the specific teaching context from microcosmic viewpoint. As to research methods, researches home tend to adopt the mixed method of empirical and non-empirical research, while researches abroad often employ combined methods of multi-empirical studies. In terms of construction of theoretical framework, both pay more attention to design study, with less attention to exploratory researches and explanatory researches. There are great differences both home and abroad in numbers of researches over application intentions and interactive subjects and in dimensions, predicting that the research on combination of blended learning and flipped class might be the primary trend for future blended teaching or learning (Ma et al., 2015; 2016).

\subsubsection{Current Teaching and Needs of Fashion Major in BIFT}

At present, Most College English teachers still conduct their class in traditional way-Teacher-centered explanation of each unit. Instead of emphasizing the application ability, they pay more attention to vocabulary, word collocation, and grammar as what high school teachers usually do, which is very dull for most students. Therefore, College English of fashion major has not yet achieved the innovative and pragmatic goal, and the following problems still exist:

1) Lack of English learning motivation results in absence of class interaction. Laziness in study has long been increased for the boring teaching content and absence of targeted learning resources outside class. It is very obvious that "one size fits all" approach in traditional class can't guarantee all students understand teaching contents and internalize the knowledge at the same time due to limitation of class periods. Besides, online to offline (OTO) blended teaching is not employed despite the fact that professional research-based English blended teaching highlights the features of classification and individualized teaching, and meets the learning needs of high-level students. Also, Micro-course, as an important part of blended teaching, is not adopted in English teaching either, although it could properly adapt to the individualized learning for its concise content, highlighted key points while breaking the temporal and spatial restraint. There are great differences in teaching progress, knowledge input among all the students with different backgrounds. Usually some students of fashion major need to stay up for preparation of specialized assignments, while others from clothes engineering of fashion major are required to finish experimental assignments, which can't guarantee the necessary time assigned to English study. Therefore, absence of change in teaching mode would not improve learning motivation at all.

2) There exists lack of integration or improper integration of English skills and professional ability, which, to some extent, affects construction and development of specialized academic English. Under the educational environment of constructing first-class specialties, the integration of English skills and professional ability is needed with times, and good command of English and professional ability would definitely facilitate professional development of those from fashion major. However, separation of English learning from professional knowledge only increases the monotonousness and simplification of language teaching, ignoring its instrumental and cultural characteristics, along with it, the false notion that English is useless would be formed among students. On the contrary, around specialized academic English, the English skill integrated with professional knowledge could enhance their learning awareness and learning motivation in terms of practicability.

3) There exists bottleneck for teachers in teaching and development. During English teaching process, only English skills are focused in traditional class, which can't motivate learning, because some students in traditional class have no interest in only grammar, syntax and etc., the similar practice in high school, while others feel doubts about the purpose of learning College English, increasingly realizing what they have learnt has no direct promotion to their professional development. As a result, teachers are confined to grammar teaching. Of course, for teachers, only vocabulary, grammar and the like are taught in College English class would lead to no progress in their professional development, especially interdisciplinary development.

In short, facing the problem above, proper reform of College English teaching would, to some extent, change the current unsatisfactory college English teaching, and promote course construction, especially the connotation construction of College English, "to impart what students really need to them."(Wu, 2019)

\subsubsection{MyCOS' Investigation of Undergraduate over Academic Activities in BIFT in 2019}

An investigation over undergraduates from BIFT was conducted by MyCOS in 2019. MyCOS, the founder and leader of management data and consulting industry of China's higher education, was founded in 2006, by which annual data tracking and consulting services are provided. It is not only the project co-operation with some institutions, including Chinese Academy of Social Sciences, Ministry of Human Resources and Social Security, China Association for Science and Technology and the World Bank, but also the sole contributor for Employment Report of Chinese College Students 
(i.e. employment blue book, published annually by social science literature press). The following is the percentage of participation in Academic activities of undergraduates during three different academic years from BIFT conducted by MyCOS in 2019.

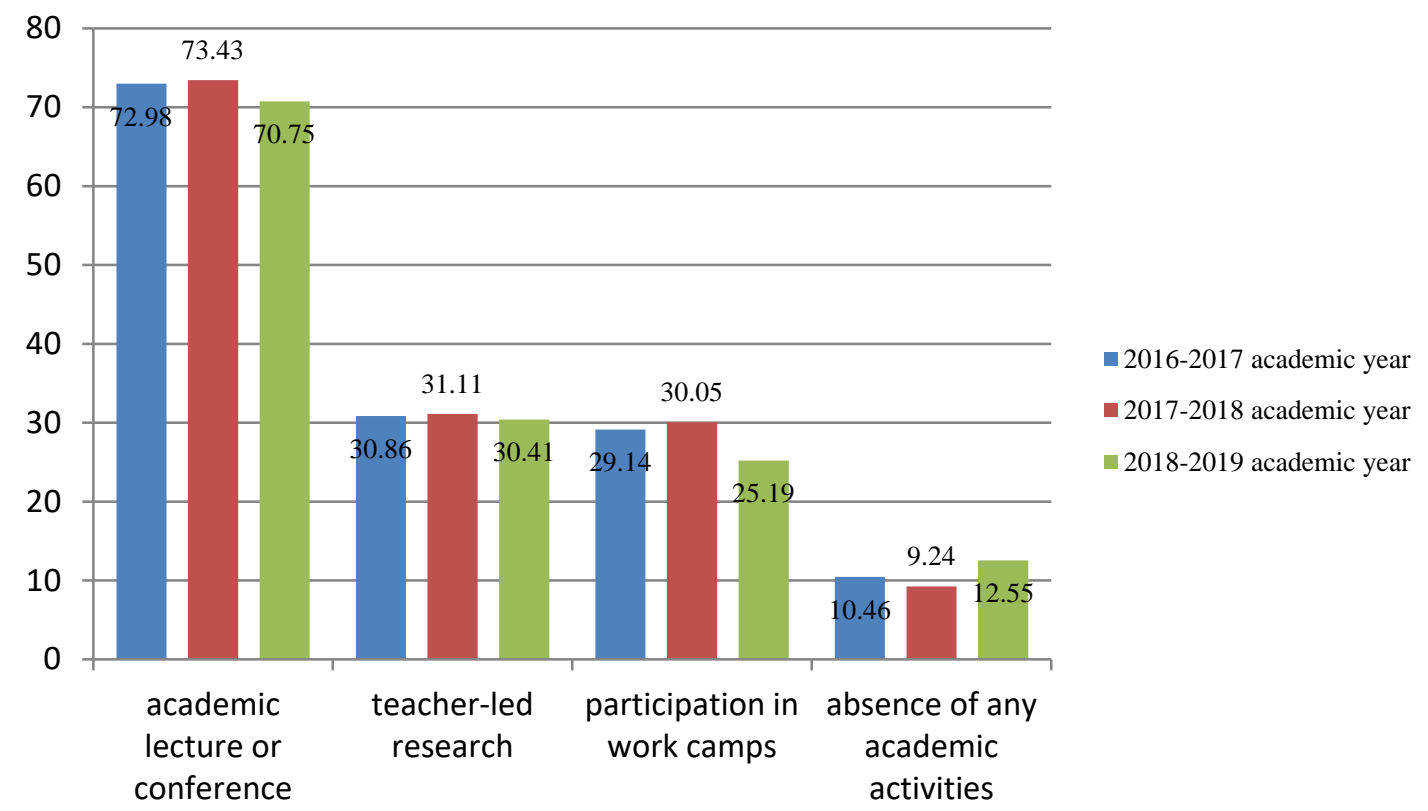

Figure 3. Participation in Academic Activities (\%)

As it is shown in Figure 3, most undergraduates have great demand for academic activities and related researches or work camps. The percentage in Figure 3 clearly shows that they actively participate in various academic lectures and seminars during three academic years. Those who participate in lectures and seminars occupy $72.98 \%, 73.43 \%$, and $70.75 \%$ respectively of the total in different academic years from 2016 to 2019 , which clearly indicates their belief in the fact that frequent participation in professional or academic activities plays a significant role in their professional development. Those who participate in teacher-led projects occupy $30.86 \%, 31.11 \%$, and $30.41 \%$ respectively of the total in three different academic years, the percentage of which tends to be stable. Undergraduates attending workshops account for $29.14 \%, 30.05 \%, 25.19 \%$ respectively during the recent three academic years, while taking part in no academic activities are relatively fewer, only accounting for $10.46 \%, 9.24 \%, 12.55 \%$. Therefore, the investigation over undergraduates above, on one hand, shows great enthusiasm and interest of undergraduates in the academic activities, and on the other hand, it suggests that undergraduates attach great importance to their professional and academic ability. Obviously, they have a great desire for improvement in their professional development, and a great need for an increase in their academic ability too.

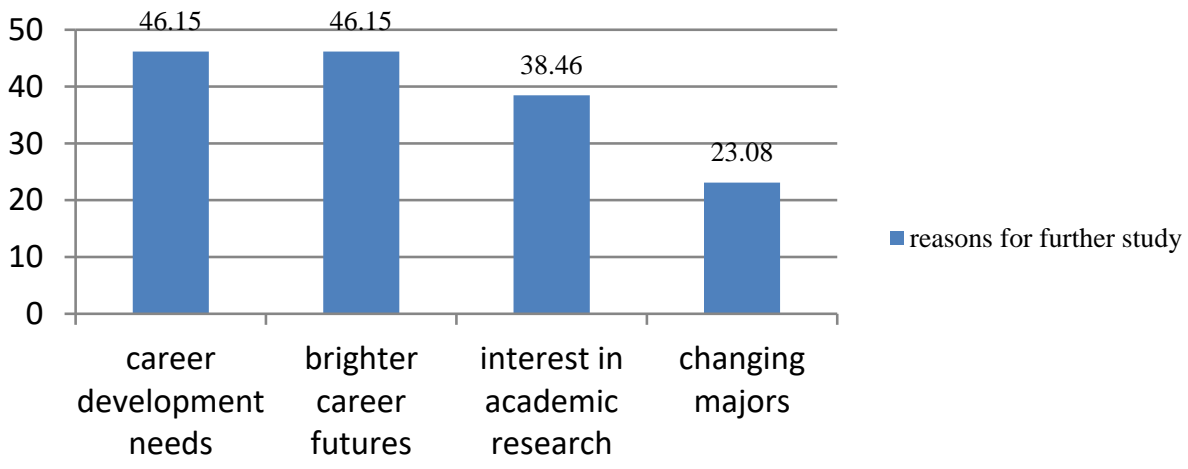

Figure 4. The Top Four Major Reasons of Undergraduates for Further Postgraduates Study (\%)

What is shown in Figure 4 indirectly shows the desire of undergraduates to improve their professional ability and academic ability by presenting the reasons for further study from investigation. This investigation is a questionnaire 
with a multi-choice for each topic, aiming at knowing their direct needs for further study. The result shows that the top four major reasons for further study are closely related to career development and academic ability, mainly including needs for employment development, consideration of career prospects, and involvement in academic researches. There is no doubt that undergraduates really value the important related abilities for future employments, such as professional plan, academic exchange or professional communication, etc., and this is supposed to be taken into consideration while designing teaching mode.

Based on the research background mentioned above, we have a clear knowledge of what undergraduates really need, what teachers are expected to do in English class, and at same time, we realize the study that we have conducted is very important for them. Above all, this research aims at constructing the new blended teaching mode in academically research-oriented College English teaching, with the blended teaching theories as the framework, Tsinghua Online teaching platform of BIFT as the support, to greatly improve the integrated English language competence and academic or professional communication skills of undergraduates.

\section{Research Oriented Blended Teaching Practice}

\subsection{Research Method}

\subsubsection{Subjects}

Fifty-four students of class Art A-levell from grade 2018 of fashion major in BIFT are chosen as the subjects. They are graded to A-level after annual admission placement test (There are three levels for each grade, including A-level, B-level and C-level. A-level is the highest one.). Those belonging to A-level have relatively a good command of English with a strong thirst for knowledge. And book-based English teaching is not enough, and can't satisfy their needs. Most of those students would start up business or pursue further study after graduation both home and abroad; therefore, they have strong desire and even eager demand for improvement in their professional ability and academic communication skills.

\subsubsection{Instrument}

Research-based blended English teaching is conducted during three semesters with fifteen-week lessons in first and second semester respectively, ten-week lessons in the third semester, and 4 hours weekly each class. Tsinghua Online teaching platform is the main learning platform, with APP of synchronization platform Quality MOOC as the assistance.

The respective professional presentation of Chinese costume culture and Western costume culture is arranged mainly during the first two semesters, while the third semester is designed for research on synchronic comparison between Chinese costume and Western costume. All are required to be finished among groups.

\subsubsection{Research Questions}

By conducting this teaching practice, we are expected to answer the following questions:

(1) In what way can undergraduates be motivated in College English learning?

(2) In what way could College English teaching be integrated with research-based teaching?

(3) Could College English research-based blended teaching help students deliver the English professional presentation independently or conduct a small academic research in English?

\subsection{Research-based English Blended Teaching}

\subsubsection{Process of Research-based College English Blended Teaching}

During College English teaching, research-based content is integrated systematically into College English teaching to achieve two purposes---one is to improve students' language skills, another is to develop students' ability to deliver a professional presentation or conduct professional or academic research while enhancing group co-operation to promote the incentive in their English studies. The specific practice is as follows:

In the first semester, research-based instructions from teachers should be introduced at course description class, and a certain class hour would be spared from each unit for research related activities. The whole class will be divided into 12 research groups, each group members are required to choose a fashion-related topic on their own or by suggestions from the teacher, which would cover different diachronic period of Chinese costume history (for first semester) and Western costume history (for second semester). Of course, before group division, the Chinese costume history and the Western costume history will also be divided into 12 periods respectively for the convenience of selection. In the first semester, all group work would focus on diachronic periods of Chinese costume history.

There are 4-6 students in each of the 12 groups, of which, a group leader is chosen in charge of the group cooperation and negotiation. There are twelve fashion-related topics representing different periods (mainly following evolution of 
Chinese costume history), one group, one topic. All the students in this class are required to deliver presentation according to the topic they choose in the group in the first semester. Those who are not able to deliver the presentation in class due to the limitation of the class period, would be required to record their presentations off-class and upload them to the column "research-based learning" on the platform for sharing, and for evaluation and rating from both teacher and their peers.

Evaluation is also multi-dimensional for the sake of full interaction and participation. Evaluation of in-class presentations is usually finished by teacher and designated group or peers, the result of which would be a part of formative assessment in this semester, while off-class presentations would be assessed on platform by other groups, and the rating is given by teacher based on what other students have evaluated. Of course, the result will be a part of formative assessment too.

In the second semester, all group work would focus on different periods of Western costume history. We follow the same teaching procedures and evaluation procedures we have followed in the first semester.

In the third semester, the further research guided by teacher would be conducted based on the presentations delivered in the first two semesters. A synchronic comparison is required to be conducted among groups. Each group leader, as the representative of the project, gives 10-minute presentation in order, based on the research result at the very beginning of each class. The report from each group must be uploaded on the platform for sharing and assessment. Rating would be given to the group as a whole, instead of rating each student individually. In order to avoid occupying the class hour for English skill teaching, flipped class teaching, regarded as the most effective and suitable teaching method for in-depth leaning, is also adopted for the convenience of blended teaching (He, 2018). Teaching content related to academic research, including academic presentation, report writing, academic research writing, etc., usually is recorded as micro course prepared before class for autonomous study. Students are required to learn out-of-class, and put forward any questions on-line or through WeChat, while the teacher is ready to respond to the questions all the time besides the 10-20 minute focused explanation of difficult points in class.

Class hour is limited, so we make use of the column "Question-\&-Answer" on the platform, or the column "discussion" on APP to solve problems or questions from students. By mutual evaluations, critique, compliments, they actively participate in those activities, showing great enthusiasm for this course. When those content is integrated into English class, the learning for my students is targeted, the relationship between English and professional knowledge is clarified, the interest is increased, and as a result, students perform more actively in English learning than ever before, and learning motivation is greatly enhanced.

\subsubsection{Adoption of Flipped Class in Research-based College English Blended Teaching}

Because of the limitation of the class hour ( 45 minutes a period), blended teaching mode is employed to make teaching more effective, and micro course facilitates blended teaching indirectly by providing students with chance for autonomous study. After before-class learning, more problems or questions will be solved by off-class discussion on platform or synchronized APP with the key and difficult points solved in the class. Videos related to academic research or writing are recorded into ten chapters as micro courses required to be watched and learnt autonomously before each unit. Procedure of research-based College English blended teaching, as is shown in Figure 5, is presented clearly in the following:

Before class, students are required to watch online micro-courses about the English text of the unit and the professional presentation or academic research, then they would finish the assignments, such as presentation and English exercises. Any problems or questions after watching would be quickly responded by teachers through the platform or WeChat.

During class, two or three undergraduates from different groups would deliver the professional presentations, and other assignments would be checked by quiz or questions, etc.. Then, teacher-conducted assessment over their performances and interactive English text learning would be followed. Before the end of the class, a summary of the main points and difficult points would be stressed by teachers.

After class, revision and reflection are required and guided by teachers, discussion and evaluation from peers are needed too on the learning platform. Undergraduates are supposed to learn further by enriching their presentations or researches, and prepare or preview what next class needs. 


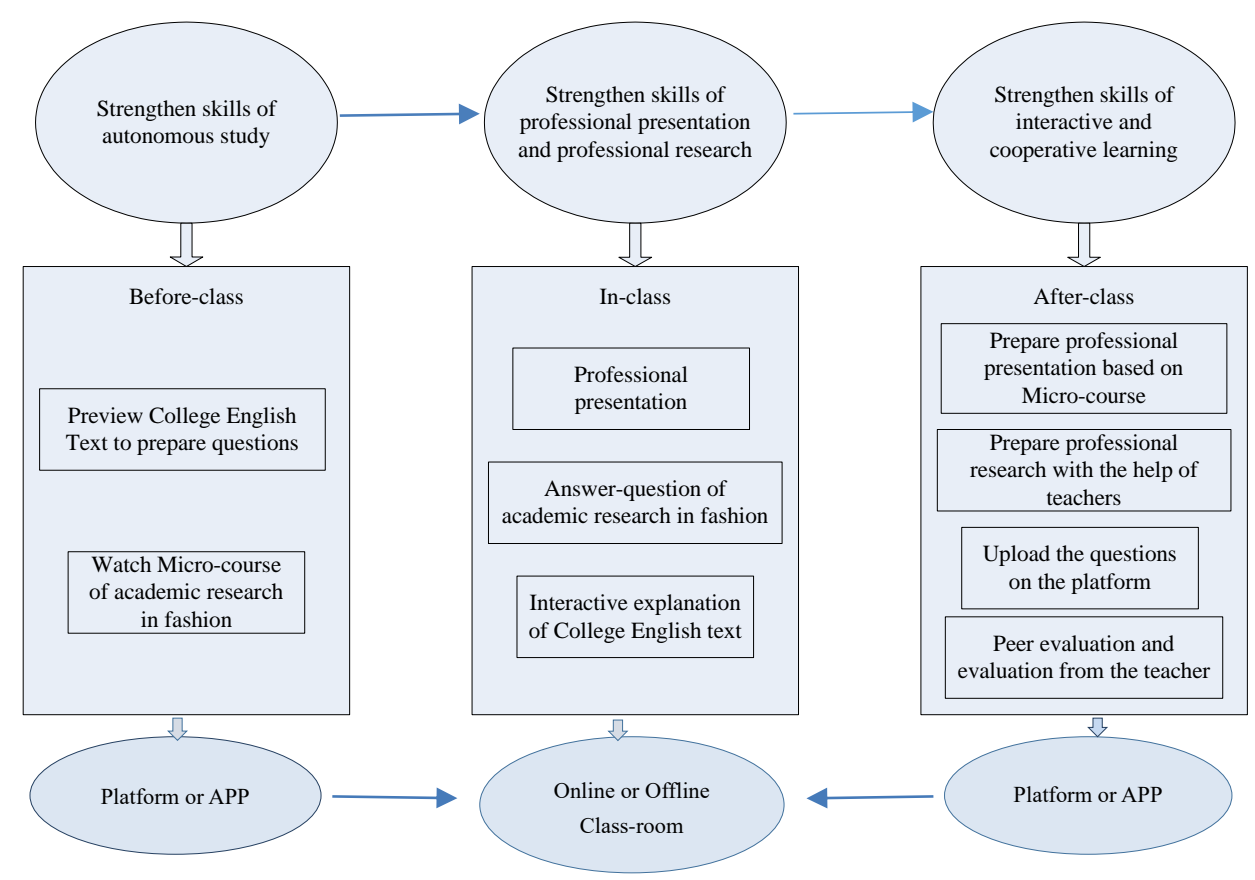

Figure 5. Procedure of Research-based College English Blended Teaching

\section{Results and Discussion}

\subsection{Research Results}

1) The in-class learning motivation is greatly stimulated, and interaction is effectively improved. Blended teaching and learning based on online and offline professional knowledge highlight the characteristic teaching of hierarchical classification and individualization, which helps reduce the laziness in English study and insufficient motivation. It is a real challenge for students to read more professional materials in English in order to make a perfect presentation and to conduct a meaningful project. However, they show great interest and persistence in work. Formative assessment covers class interaction, and most students get the satisfactory marks by actively participating in interaction with more questions at the end of each academic year.

The difference of students' demands determines the reform of teaching modes. Besides the basic knowledge of this course online to satisfy learning needs from most students, such as unit news listening, online watching and listening practice and off-class online listening extension, professional research related micro course is also added. If doubtful about any points in class, students can review online with online "discussion" for more interaction (as is shown in the Figure 6). For those who have high English proficiency, learning expansion is provided which is called "fashion readings and reviews" to broaden their professional vision. 


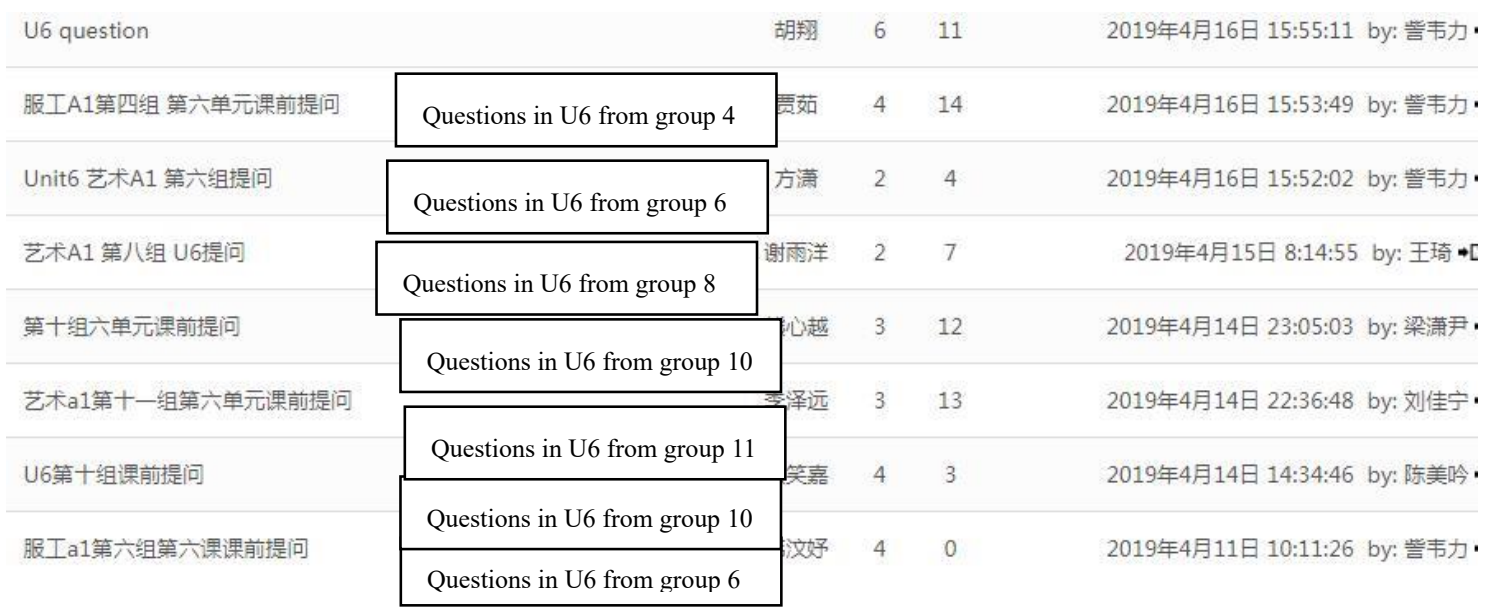

Figure 6. Part of Interface for "Question-\&-Answer"

Students can log on the course by App in mobile phone for autonomous study with free arrangement of time, which helps make up for lack of class time and avoid incomplete acceptance of in-class content. Despite of most occupied time by professional assignments from specialized teachers, they could steal time for autonomous study and other assignments from this class. Each unit covers basic skills practices, such as before-class listening, micro courses, unit focus, and after-class extension, etc.. It especially adds micro courses related to fashion research, fashion reading and review and fashion presentation etc.. Active study promotes satisfactory school performances. During the first two semesters, twenty students selected from this class by school have passed National College English Band 4 examination, and six students have got excellent marks for IELTS, waiting for further study abroad. So, higher motivation and great enthusiasm for learning could indirectly improve language proficiency.

2) Instead of monotonous teaching in English class, the professional knowledge is effectively integrated into English class, where students are guided to learn to deliver professional presentation and conduct a small professional academic project in English, which also promotes the construction and development of English for academic purposes. As it is shown in Figure 7 and Figure 8, to construct high-level specialty depends on quality teaching and high-class cultivation of talents with broadened international perspective and strong professional communication skills.

Therefore, the research-based blended teaching greatly improves language proficiency of the students of fashion majors, strengthening their international communication skills, which indirectly lays a solid foundation for enhancing the ability of fashion talents and sufficiently prepares for reserve fashion talents.

In the latter half of 2019, two students in this class-Zeyuan Li and Ruanci Yang, won the 2th prize and the 3th prize respectively in "Guo Cai Cup" National College English Reading and Writing Contest. In the same year, another 6 students won the second and third prize respectively in National English Contest for College Students (NECCS) in China. Those honors suggest that motivation and interest in learning and integration of language learning with professional knowledge would help broaden their vision and thus promote the language competence.

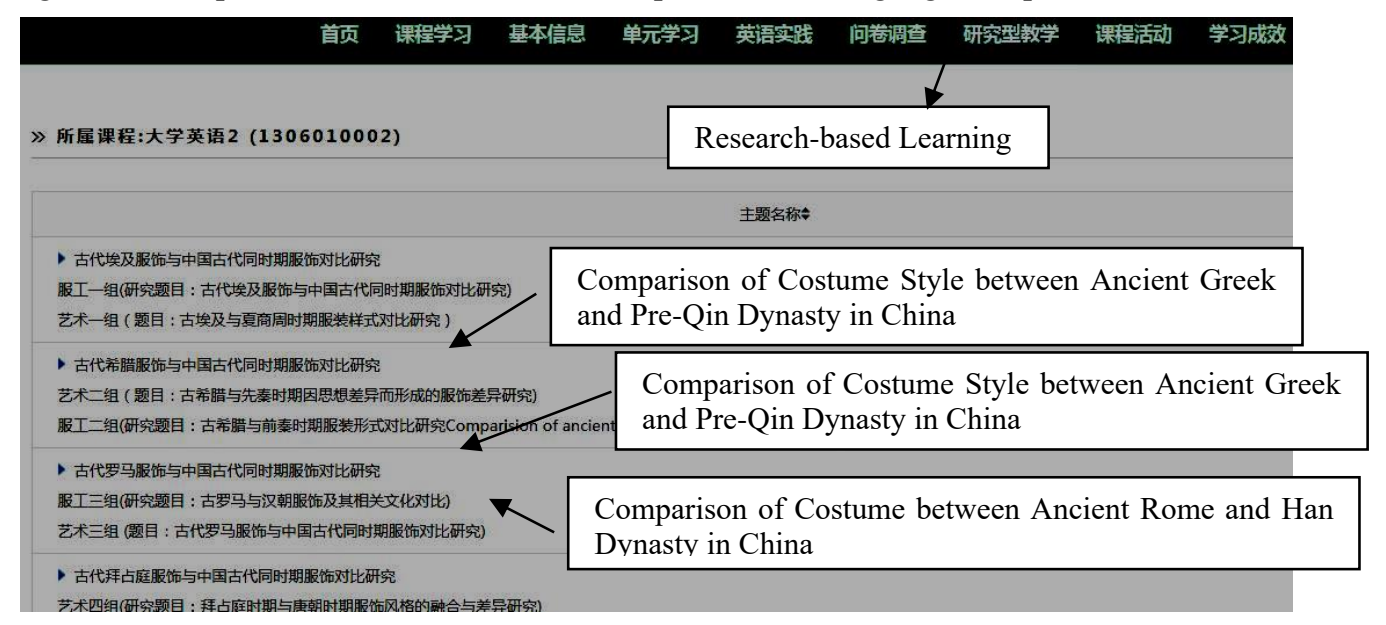

Figure 7. Part of Interface for "Research-based Learning" 

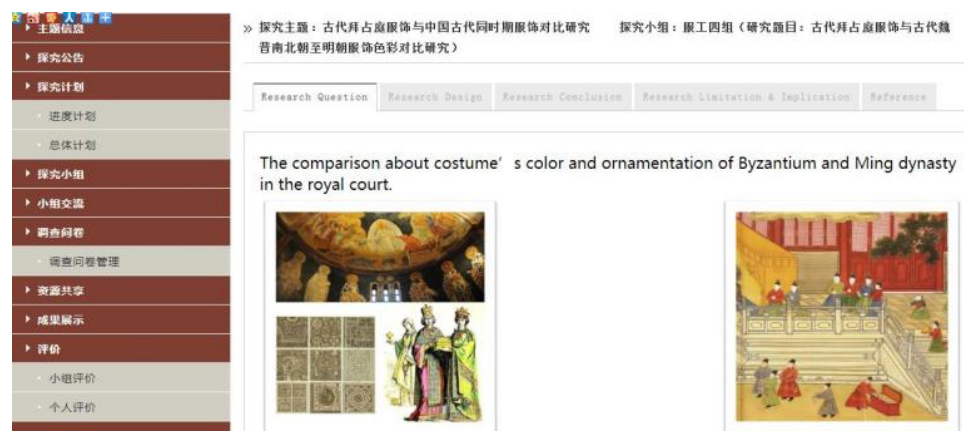

Figure 8. Part of Interface for Group Exploration in Research-based Learning

Students are required to work in groups based on the chosen topic, and finish English academic presentations during the first two semesters (see Figure 9). As it is known, group work is like learning community, where all group members share resources and learn together, share feedback and discussion from each other, (He, 2018) and the learning efficiency is obviously doubled.

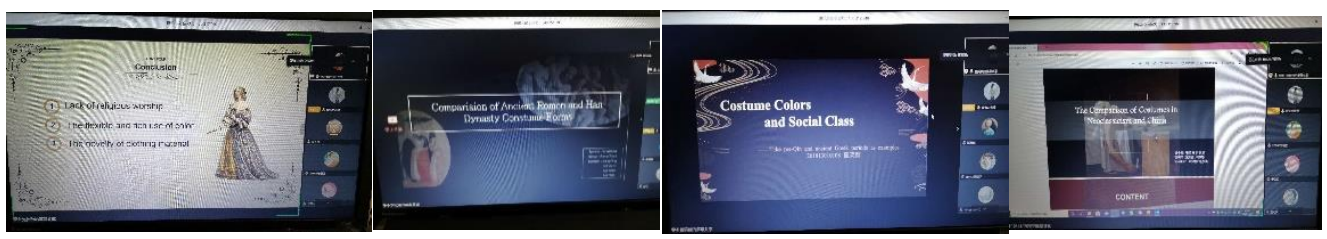

Figure 9. Part of Online Screen Capture of Academic Presentations

All will participate collaboratively in professional research led by the group leader (research language: English), learning research procedure, consolidating the professional learning, strengthening English skills to improve their comprehensive ability.

While conducting research-based blended teaching, it is not only necessary for teachers to have clear thinking and direction over blended teaching, but also essential for them to have certain professional knowledge and research ability. This high demand could prepare teachers to respond to any professional knowledge related questions from students, which would finally achieve interactive learning. Above all, highly motivated learning definitely optimizes teaching in English and enhances the teaching effect. In the second half of 2019, one group of the class successfully applied for Undergraduates Research Training Programs (URTP) with the research topic "A Comparative Study of Western and Chinese Clothing Fabrics in the Late 19th and Early 20th Century".

3) Bottleneck for teacher in teaching and development is alleviated. To be a College English teacher, is it correct to teach only English knowledge, and ignore the relationship between the English skill and the professional knowledge? Is it beneficial to professional development for both students and teachers? Of course, integration of the professional knowledge of fashion major with English skill in English class helps students find the promotion of English skill to their professional development, which indirectly enhances their interest in English and active participation in research-based learning. At the same time, expertise is needed to be supplemented for teachers, which not only poses a big challenge in teachers' professional development, but also opens up the infinite space for them.

\subsection{Inspiration from Research-based Blended Teaching}

The integration of course teaching and professional knowledge with the involvement of information technology could facilitate blended teaching to realize teacher-led roles and student-oriented position in new teaching environment, which is characterized by autonomy, exploration and collaboration to achieve the fundamental change of classroom teaching structure (He, 2017). While great results from research-based teaching have been achieved in a blended environment, the following issues are supposed to be paid attention to.

1) There should be a systematic guidance from teachers. During research-based teaching process, every knowledge point and link should be presented to students systematically from the rules of presentation to the framework of studies.

2) Roles in group should also be kept clear. Responsibility of group leaders should be clarified and defined, and all group members are required to participate in the researches. After research, evaluation from teachers and peers is quite essential. 
3) The professional quality of teachers should be improved constantly, for their professional knowledge decides the depth and width in teaching research. Because teachers are the foundation of education, they are required to involve themselves in in-depth study sustainably for professional knowledge to improve quality of research-based teaching.

4) Blended teaching should be constantly optimized. Obviously, blended teaching promotes the efficiency in College English teaching by optimized teaching and learning time. And with further optimization in blended teaching mode, research-based blended teaching is to be found more convenient for learning and more popular among students.

\section{Conclusion}

College English teaching is a part of general education in higher education, which is responsible for cultivation of international fashion talents with strong professional competence and profound academic learning. Therefore, need for more international specialized fashion talents urges constant and timely construction of course, and innovation in College English teaching urges the fundamental change of traditional class-teaching structure. Above all, based on OTO blended teaching mode, research-based College English teaching is innovatively explored and practiced through in-depth integration of English teaching and specialty with involvement of modern information technology, to satisfy the needs of students from fashion majors, which further helps improve professional skills and ability, and promote their academic communication ability as well. And this would not only be significant but also exemplary in cultivation of international fashion talents.

\section{Acknowledgement}

This study, as a phased achievement, has been funded by the key project of education and teaching in BIFT "Construction of Micro-course in Specialized Academic English" (JGZD-1710)

\section{References}

He, K. K. (2004). On the New Development of educational Technology Theory from the perspective of Blending Learning (first part). China Educational Technology, 3, 5-10. https://doi.org/10.13811/j.cnki.eer.2004.03.001

He, K. K. (2017). The Deep Integration of Information Technology and Subject Teaching. Educational Research, $10,89$. http://kns.cnki.net/kcms/detail/detail.aspx?FileName=JYYJ201710014\&DbName=CJFQ2017

He, K. K. (2018). Deep Learning: The Change of Learning Style in the Internet Era. Educational Research, 5, 111-115. http://kns.cnki.net $/ \mathrm{kcms} /$ detail/detail.aspx?FileName $=J Y Y J 201805019 \& D b N a m e=C J F Q 2018$

Huang, T. E., \& Li, L. G. (2014). A Probe into Blended Teaching Mode of College English Based on Blackboard Network Teaching Platform. Theory and Practice of Education, 34(06), 55-57. http://kns.cnki.net/kcms/detail/detail.aspx?FileName=JYLL201406022\&DbName=CJFQ2014

Liao, G. F., \& Zou, X. P. (2019). The Triggering Effect of Optimizing Teaching Design on Students' Autonomic Learning and Deep Learning. Education Research Monthly, 10, 105-111. https://doi.org/10.16477/j.cnki.issn1674-2311.2019.10.015

LiuHuang, L. Z., Huang, R. H., Zhu, L. L., \& Zheng L. Q. (2005). An Action Study of Blended Teaching. Academic Degrees \& Graduate Education, 11, 5-9. https://doi.org/10.16750/j.adge.2005.11.002

Ma, Z. Q., Kong, L. L., \& Zeng, N. (2015). Analysis on the Research Trend of Mixed Learning in Recent Ten Years in China. Modern Distance Education, (06), 73-81. 10.13927/j.cnki.yuan.2015.0069

Ma, Z. Q., Kong, L. L., \& Zeng, N. (2016). Hotspots and Trends of Domestic and International Blended Learning Research-Based on the Comparison of SSCI and CSSCI Papers Between 2005 and 2015. Modern Distance Education Research, 4, 49-57+102. https://doi.org/10.3969/j.issn.1009-5195.2016.04.006

Suo, G. F., \& Chi, R. B. (2018). A study on the MOOCs-based blended intercultural foreign language teaching. Foreign Language World, 3, 89-96. http://kns.cnki.net/kcms/detail/detail.aspx?FileName=WYJY201803013\&DbName=CJFQ2018

Wang, L. L. (2017). A Design of SPOC-based Blended College English Teaching Model. Heilongjiang Researches on Higher Education, 10, 168-170. http://kns.cnki.net/kcms/detail/detail.aspx?FileName=HLJG201710040\&DbName=CJFQ2017

Wu, Y. Department of Higher Education, (2019). New mission, big pattern, new liberal arts, big foreign language. The field report of the 4th National High-level Forum on the Reform and Development of Foreign Language Education in Institutions of Higher Learning. Retrieved from https://xkb.xisu.edu.cn/info/1056/1170.htm

Yang, F., Wei, X., \& Zhang, W. X. (2017). An Exploration of Blended English Teaching Model. Technology Enhanced Foreign Language Education, 1, 21-28. 
http://kns.cnki.net/kcms/detail/detail.aspx?FileName=WYDH201701004\&DbName=CJFQ2017

Yu, S. Q., Lu, Q. L., \& Chen, S. J. (2005). Mixed Teaching in Network Environment-a new teaching mode. China University Teaching, 10, 50-56.

http://kns.cnki.net/kcms/detail/detail.aspx?FileName=JXCY200510023\&DbName=CJFQ2005

Zhang, X. Y., \& Qi, J. H. (2019). Research on the Blended Language Teaching Model based on RCoI Survey-Taking the "College English" Course in Shenzhen University for Example. Modern Educational Technology, 29(09), 66-72. https://doi.org/10.3969/j.issn.1009-8097.2019.09.010

\section{Copyrights}

Copyright for this article is retained by the author(s), with first publication rights granted to the journal.

This is an open-access article distributed under the terms and conditions of the Creative Commons Attribution license which permits unrestricted use, distribution, and reproduction in any medium, provided the original work is properly cited. 